\title{
La televisión llega a la publicidad. Prácticas publicitarias e imagen femenina en Costa Rica
}

\section{Television Reaches Advertising. Advertising Practices and Female Image in Costa Rica}

\author{
Virginia Mora Carvajal
}

\begin{abstract}
Resumen
Este artículo analiza la publicidad impresa costarricense de televisores, básicamente las prácticas publicitarias utilizadas para introducir el nuevo medio de comunicación en el país, así como la utilización que en ellas se hace de la imagen femenina para el logro de tal objetivo en la década de 1960, ya que fue precisamente en ese año que se inaugura el primer canal de televisión en Costa Rica. Para ello se utilizan como fuente los primeros anuncios impresos sobre televisores publicados en los periódicos Diario de Costa Rica y La Nación durante ese período. La investigación permitió determinar las estrategias publicitarias utilizadas por las distintas marcas para introducir sus aparatos de televisión en el país, establecer las principales marcas publicitadas y sus características y, finalmente, explicar los rasgos básicos del uso de la imagen de las mujeres en estos anuncios, así como plantear algunas posibles explicaciones al respecto, en términos del papel de estas como consumidoras y de la televisión como una nueva forma de entretenimiento para ellas situada directamente en el seno del hogar.

Palabras clave: Historia de la comunicación, Publicidad impresa, Comunicación audiovisual, Televisión comercial, Mujer.
\end{abstract}

\begin{abstract}
This article analyzes Costa Rican print advertising for television screens and the use of the feminine image on it. Also, its relationship with femininity conceptions prevailing in the decade of 1960, since it was precisely at the beginning of this decade when Costa Rica inaugurates the first television channel, subject that has been unexplored in the national context. Therefore, the first print advertisements about television screens that were published during that period in Diario de Costa Rica and La Nación newspapers are used as sources. The research allowed to determine the advertising strategies used by the different brands to introduce their television screen sets in the country, to establish the main brands advertised and their characteristics, and finally, to explain the basic features of women image in these ads. It also helped to raise some possible explanations in this regard, in terms of women role as consumers and television screens as a new way of home entertainment for them.

KeyWords: History of communication, Print advertising, Audiovisual communication, Commercial television, Woman.
\end{abstract}

1. Centro de Investigación en Comunicación (CICOM), Universidad de Costa Rica, Costa Rica, virginia.mora@ucr.ac.cr

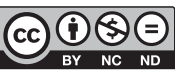




\section{Introducción}

En mayo de1960, a pocos días de haberse inaugurado las transmisiones de televisión en Costa Rica por medio del hasta hoy canal nacional Teletica Canal 7, se publica en el periódico La Nación un anuncio de la marca de televisores Philips que hacía referencia a tal hecho de la siguiente manera: «tenemos televisión! Desde hoy Costa Rica quedará en contacto con el mundo, no a distancia, sino desde muy cerca» ${ }^{1}$. Este anuncio que alababa las bondades del nuevo medio de comunicación aduciendo que a través de un televisor -Philips por supuesto- «...el mundo es de usted en imágenes nítidas y sonido de alta fidelidad...» ${ }^{2}$, acompañaba su texto con la imagen de una mujer que salía de la pantalla de un televisor, una mujer joven y bien arreglada, cuyo cuerpo se apreciaba hasta la cintura en la nueva pantalla, viste además un elegante y escotado vestido -Figura 1-. Pero ¿qué relación había entre la llegada de un nuevo medio de comunicación y una figura femenina?

Figura 1

Anuncio de televisores

Philips, 1960

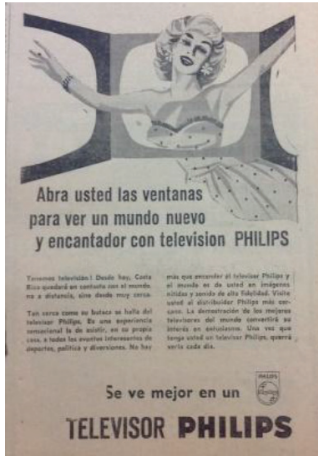

Fuente: La Nación, 16 de mayo de 1960: 1.

Lejos de darse esta relación solo en el anuncio citado, al analizar en detalle la publicidad de televisores de la década de 1960, resulta más que evidente que la asociación anterior más que una casualidad es una constante en los anuncios del período, por ello se considera relevante dedicar esta investigación precisamente a indagar el porqué de dicha relación y sus posibles vinculaciones con el contexto familiar en el cual probablemente se buscaba ubicar la promoción de los televisores, así sus posibles relaciones con las concepciones de lo femenino imperantes en la Costa Rica de la década de 1960.

Adicionalmente, dentro de la publicidad de electrodomésticos de la época, la gran novedad era precisamente la llegada de los televisores al país, de ahí que también interese conocer cómo era la publicidad de éstos y como se promocionaban en un contexto en el cual apenas estaba emergiendo el nuevo medio.

Dado que se trata de un estudio de carácter exploratorio, es importante señalar que, en cuanto a los antecedentes de esta investigación, el trabajo que abarca de mejor forma la introducción de la televisión al país es uno de Patricia Vega del año 1987, en el cual la autora mediante la revisión de diversas fuentes trata de contextualizar y de explicar los inicios de la televisión costarricense.

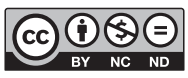


Vega explica las disputas políticas que la introducción de la televisión generó en el país, básicamente entre el grupo liderado por el Partido Liberación Nacional, promotor de una televisión en manos del Estado y, el grupo económico que le adversaba y que venía gobernando al país desde la primera mitad del siglo XX, cuyo objetivo era fundar un primer canal de televisión que estuviera en manos privados. Finalmente, esto sucede en el gobierno de Mario Echandi Jiménez, cuando en 1960 se autoriza la concesión de la frecuencia de canal 7 al empresario René Picado y al ingeniero Carlos Manuel Reyes (Vega 1987). Asimismo, el periódico La Nación publicó en agosto del 2017, un especial dedicado a la llegada de la televisión al país, el cual se complementa con material gráfico acerca de ese acontecimiento, tomado del mismo periódico (Corrales 2017).

En cuanto al campo de la publicidad, no hay estudios nacionales anteriores acerca de la misma en relación con los televisores ni mucho menos, en cuanto al papel de las mujeres dentro de ella. No obstante, un trabajo interesante al respecto es el de Hill (2002), en el cual el autor dedica un pequeño apartado a la importancia que las mujeres tenían para las empresas productoras de televisores en el contexto de los Estados Unidos, pues al considerarlas "árbitras de la cultura en el hogar" (Hill 2002, 31), reconocían su influencia en la compra de estos aparatos, así como su papel de consumidoras de los nacientes programas televisivos en la década de 1950, de ahí la importancia de incluir en ellos temas que les interesaran a las mujeres, reconociendo la necesidad de convertirlas en público consumidor de los mismos en el hogar.

Adicionalmente, existen bases de datos digitales de anuncios publicitarios sobre televisores de distintas marcas, en los cuales se observa la misma tendencia a utilizar la imagen de las mujeres, tal y como se estudia en esta investigación. Una de ellas es la que ofrece la Universidad de Duke, en la que se exponen anuncios publicitarios de televisores para el período 1939-1957, la cual, si bien es anterior a la década estudiada, sirve de contexto para el caso costarricense, además de que los anuncios que se publicaban en Costa Rica eran prácticamente copias o adaptaciones de los de Estados Unidos.

Otra base de datos disponible es The Advertising Archives, más vinculada al ámbito europeo, que incluye anuncios publicitarios desde mediados del siglo XIX hasta la actualidad y cuyas colecciones están ordenadas por décadas. También es importante mencionar el libro editado por Jim Heimann (2005), en el que se presenta una colección de anuncios publicitarios de los Estados Unidos para la década de 1960, entre los cuales hay anuncios referentes a la publicidad de televisores de marcas como Motorola y Sony, también publicitadas en Costa Rica.

Así pues, el objetivo de este trabajo es analizar las estrategias publicitarias utilizadas para introducir la televisión en el país, así como la utilización que en ellas se hace de la imagen femenina, en la década de 1960. En concordancia con este objetivo, se plantean las siguientes preguntas de investigación: ¿Cuáles son las características que presenta la publicidad de televisores? ¿Cómo se vende la idea de comprar un aparato de televisión cuando el nuevo medio apenas iniciaba en el país y cuyas transmisiones no eran continuas? ¿Por qué se asocia esta publicidad con la imagen de las mujeres? ¿Cuál es la relación del nuevo medio de comunicación con las costarricenses en los albores de la televisión nacional? ¿Qué tipo de mujeres y en qué contextos se representan en la publicidad de televisores? ¿Cómo se vincula la llegada de un nuevo medio de comunicación con el contexto social costarricense del período?

Desde esa perspectiva, las fuentes utilizadas en este estudio son 130 anuncios publicitarios publicados en los periódicos Diario de Costa Rica y La Nación durante la década de 1960, 31 -24\%corresponden al primero, mientras que el segundo contribuye con 99 anuncios $-76 \%-$. Cabe señalar que el Diario de Costa Rica está disponible en formato digital en el portal del Sistema Nacional de Bibliotecas (SINABI), pero solo para los años comprendidos entre 1960 y 1964. Por su parte, La Nación cubre toda la década y no está digitalizado, pero puede consultarse directamente en la Biblioteca Nacional.

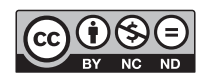

Rev. Reflexiones 98 (2) Julio-Diciembre, 2019: 39-64, E-ISSN: 1659-2859 
Estos anuncios fueron analizados considerando aspectos como los siguientes: las marcas publicitadas, las formas de promoción utilizadas por ellas, los avances tecnológicos que destacan las distintas marcas, las imágenes utilizadas (televisores, familias, personas solas o acompañadas), las imágenes de mujeres que se usan (edad de las mujeres, espacios en que aparecen, vestuario, si están solas o acompañadas), las imágenes que aparecen en los aparatos de televisión, el tamaño de los aparatos de televisión en relación con las mujeres que aparecen en los anuncios, entre otros. Posteriormente el material se organizó en tres grandes ejes temáticos a los que responden los apartados de este estudio: las características de la publicidad de televisores; las marcas publicitadas y sus principales puntos de diferenciación y/o similitudes; y la relación entre esa publicidad y la utilización de la imagen de las mujeres.

Finalmente, el trabajo se estructura en tres apartados. El primero titulado Generalidades de la publicidad de televisores, establece las principales tendencias publicitarias del nuevo medio, mientras que el segundo denominado Marcas publicitadas, caracteriza las marcas de televisores localizadas en la publicidad del período, tratando de determinar sus similitudes, diferencias y particularidades. El tercer apartado, titulado Publicidad televisiva y mujeres, tiene el propósito de establecer los puntos básicos de relación entre la publicidad de televisores y su utilización de las imágenes de mujeres, tratando de comprender el porqué de esa relación y su posible vinculación con la televisión como nuevo medio de consumo y de entretenimiento para las mujeres. El trabajo concluye con un apartado de reflexiones finales.

\section{Generalidades de la publicidad de televisores}

En mayo de 1960 se inauguran las transmisiones televisivas en Costa Rica con las primeras emisiones de Teletica Canal 7, un canal de televisión que mantiene vigencia hasta la actualidad (Vega 1987). En tal sentido, a partir de ese momento surge una cantidad importante de anuncios publicitarios impresos que promocionan la compra del nuevo aparato de televisión. ¿Cómo lo hacen? Precisamente eso es lo que se busca dilucidar en este apartado, buscando establecer algunas tendencias básicas que presenta la publicidad de televisores en el país.

Al respecto es importante recordar que la televisión se inserta en un país cuya población alcanza por primera vez el millón de habitantes de acuerdo con el Censo de Población de 1963 y cuya distribución por sexo es prácticamente similar. Además, es una sociedad en la que su población es mayormente rural, en la que la provincia de San José es ya la más poblada del país (Dirección General de Estadística y Censos, 1966a, 1).

Si bien desde la década de 1950 la publicidad de electrodomésticos en general se incrementa en el país, ofreciendo una amplia gama de enseres domésticos, como refrigeradoras, cocinas, lavadoras y planchas entre otros, no es sino hasta la década siguiente que se comienza a percibir un cambio importante: la introducción de electrodomésticos vinculados más bien al entretenimiento familiar.

En efecto, en la década de 1960 se publicitan radios, consolas, equipos de sonido y tocadiscos - con la respectiva venta de discos asociada a ellos- y, por supuesto, los televisores, considerados como la máxima expresión del entretenimiento que se podría lograr en el período estudiado. Asimismo, no es casual que justo en esta década surja la publicidad de televisores, considerando la introducción del nuevo medio en el país en 1960, pero ¿qué características presenta esta publicidad?

En primer lugar, tal y como lo indica el gráfico de la Figura 2, la mayor cantidad de anuncios se concentran en los dos extremos de la década, es decir, en 1960 y 1969, mientras que, en los años

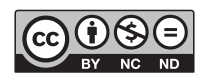

Rev. Reflexiones 98 (2) Julio-Diciembre, 2019: 39-64, E-ISSN: 1659-2859 
intermedios, la tendencia es hacia la disminución. No obstante, la mayoría de los anuncios se ubican en el primer quinquenio de la década, que suma un total de 79 anuncios, mientras que el segundo quinquenio presenta 51 e incluso para el año 1967 no se localizan anuncios.

Figura 2

Distribución de los anuncios de televisores por año, década de 1960

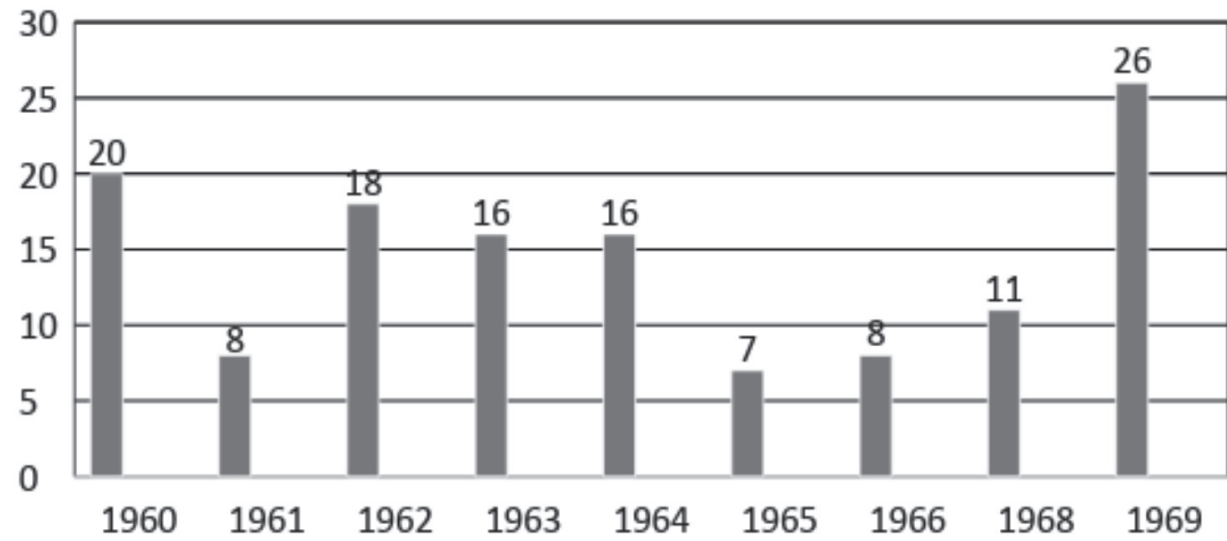

Fuente: Elaboración propia a partir de los anuncios publicitarios recopilados de los periódicos Diario de Costa Rica (1960-1964) y La Nación (1960-1969).

Ahora bien, ¿por qué los anuncios se concentran en 1960 y 1969? Ello es explicable en la medida en que en 1960 el elemento novedoso jugó un papel fundamental, es decir, se estaba a las puertas del desarrollo de un nuevo medio de comunicación que se podía utilizar directamente en el hogar, mediante la compra de un aparato de televisión. En este sentido, la televisión tiene una similitud importante con otro medio como la radio, pues ambos llegan directamente a los hogares, uno con audio y otro con audio y además imágenes, una verdadera novedad en la Costa Rica de inicios de los años sesenta.

Por supuesto que la publicidad no desaprovechó la oportunidad de utilizar la novedad como un elemento central de sus mensajes, pero también utiliza argumentos relacionados con las mejores características de los televisores ofrecidos. Por ejemplo, en 1960 la marca Philips destaca que «se ve y se escucha mejor... si es Philips su televisor ${ }^{3}$, mientras que esa misma marca subraya en noviembre de 1960 que sus televisores ofrecen «realismo en imagen y sonido» ${ }^{4}$.

También en 1960, Philips enfatiza el realismo de la imagen televisiva de sus aparatos de televisión, al presentar la imagen de un gato mirando de cerca un televisor que tiene la imagen de un pez, la cual se acompaña del siguiente texto «realismo en imagen y sonido» ${ }^{5}$-Figura $3-$.

Por su parte, National enfatiza en la «calidad, belleza y economía» de sus televisores, en un anuncio cuyo encabezado es más que significativo «por fin llegó» en alusión tanto a la llegada de la televisión como de los televisores de esa marca ${ }^{6}$, mientras que Zenith apuesta por la «calidad» para promocionar sus televisores, portátiles y de mesa, ofreciendo además «sonido libre de estática» ${ }^{7}$.

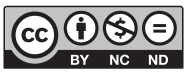




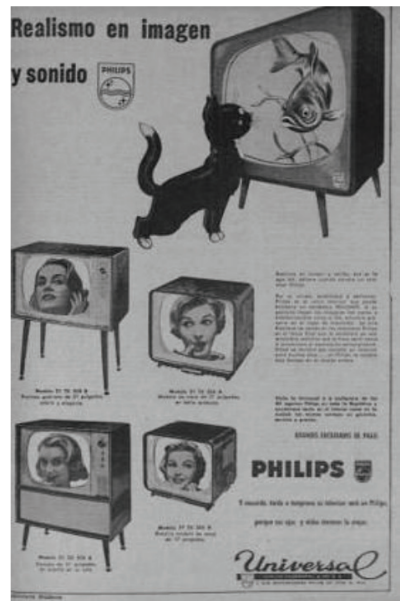

Fuente: Diario de Costa Rica, 11 de noviembre de 1960: 3

En el año 1961, la gran novedad la presentan los televisores Zenith, primero con su «sintonizador dorado» que «proporciona la mejor recepción de TV, aun en lugares donde la señal llega débil» ${ }^{8}$ y, segundo, con la oferta de televisores de 19 y 23 pulgadas ${ }^{9}$. Una novedad importante surge en 1962 cuando se anuncia que ahora se podrán ver dos canales de televisión en Costa Rica: Teletica Canal 7 y Tic Tac Canal $9^{10}$, mientras que la otra novedad la presenta Zenith con su «comando ultrasónido» -el antecesor del control actual- mediante el cual «con sólo apretar botones se enciende o apaga el televisor, cambia canales y ajusta el volumen, sin levantarse de su asiento» ${ }^{11}$.

Sobre este anuncio cabe destacar dos elementos. Uno, no es casual que aparezca este «comando» cuando se anuncia que ahora se pueden ver dos canales en el país, lo cual implicaría comúnmente el tener que levantarse del asiento para cambiar entre uno y otro $\mathrm{y}$, dos, el novedoso «comando» aparece controlado por un hombre muy sonriente, pese a que los dos televisores que aparecen a su lado proyectan imágenes de mujeres, tal y como se aprecia en la Figura 4.

También en 1962, Philips ofrece una «sintonización totalmente automática», que permite sintonizar los canales una sola vez sin que se requieran luego más ajustes, alcanzando una sintonización horizontal y vertical de forma automática ${ }^{12}$.

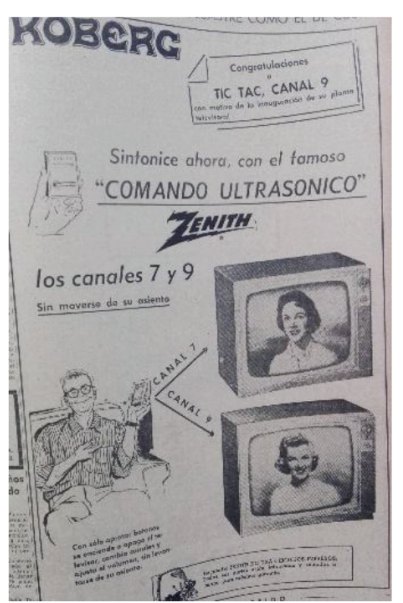


Asimismo, Sanyo ofrece el control remoto «Super Son-R», con el cual se puede «encender el televisor, cambiar de canal, ajustar el sonido en tres tonos y apagar el televisor» a una distancia de hasta 10 metros, con solo decir la palabra «sonar» ${ }^{13}$.

En el año 1963, sobresale la portabilidad de los televisores, tal es el caso del televisor Sanyo de 14 pulgadas $^{14}$; el de 19 pulgadas de Zenith $^{15}$ y el Westinghouse de 19 y 23 pulgadas $^{16}$.

Otro elemento que destaca en la publicidad de 1963 es el hecho de que, a los modelos de televisores portátiles y de mesa, se une el tipo consola, que básicamente se caracteriza por tener un mueble mucho más compacto, como el que promociona la marca Zenith de 23 pulgadas en diciembre de $1963^{17}$.

En el año 1964, se mantienen las características anteriores, a las que se añaden los televisores Sanyo de 16 y 21 pulgadas ${ }^{18}$ y, quizá la novedad más relevante en la publicidad de este año es un televisor Sony de 5 pulgadas «...el más pequeño del mundo totalmente transistorizado...» ${ }^{19}$, el cual, además, añade un elemento de portabilidad importante al poder usarse «...con "batería seca o con la batería del carro de $12 \mathrm{~V}^{2}{ }^{20}$.

Nótese como ahora la portabilidad del televisor funciona no solo en el hogar, sino también que este puede llevarse en el carro, por ejemplo, cuando se viaja con la familia, aunque también se puede colocar en la mesa de noche o en el escritorio. De hecho, en el anuncio de este televisor, aparecen dos niñas disfrutando del pequeño aparato, con la intención de brindar una sensación de familiaridad al uso del televisor en cuanto tal -Figura 5-.

Figura 5

Anuncio de televisores Sony, 1964

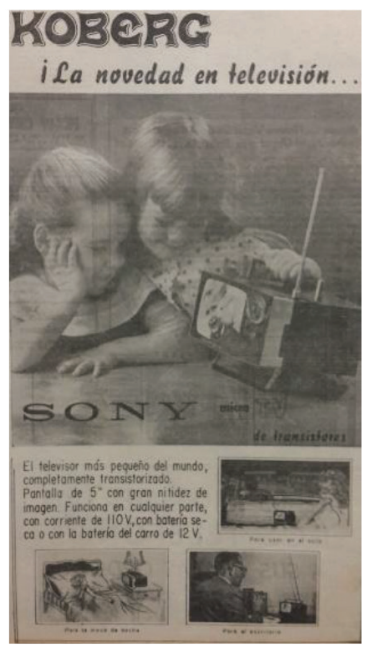

Fuente: La Nación, 5 de enero de 1964: 17.
Hacia mediados de la década, en 1965, en los siete anuncios que corresponden a este año, destaca nuevamente el aspecto de la portabilidad del televisor, esta vez con la oferta del Zenith de 12 pulgadas, el «acompañante» que «se lleva fácilmente de un lugar a otro» ${ }^{21}$, mientras que, en 1966 , lo que destaca son los modelos de televisores de mesa con controles al frente, al lado derecho de la pantalla, como el de Sanyo de 19 pulgadas $^{22}$ y el Philips de 19 pulgadas, que posee «cuatro controles al frente...»23.

En el año 1968, Philips introduce la «memoria automática» la cual «regula, sintoniza y selecciona la mejor imagen» ${ }^{24}$. Cabe apuntar que esta memoria toma la forma de una mujer una androide femenina- que tiene una especie de casco sobre su cabeza y que, además, «habla» en primera persona, pues el texto que la acompaña está escrito así «yo regulo, sintonizo y selecciono

la mejor imagen para USTED siempre $»^{25}$-Figura 6 -. Este punto es necesario destacarlo, pues se parte del hecho de que esa «memoria» está al servicio de la persona que utiliza el televisor, pero, dado que se le asigna la forma de una mujer, da la impresión de que nuevamente se asume la idea de que es finalmente una mujer la que está al «servicio» de un hombre, aunque se trate de la pieza de un televisor.

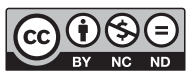




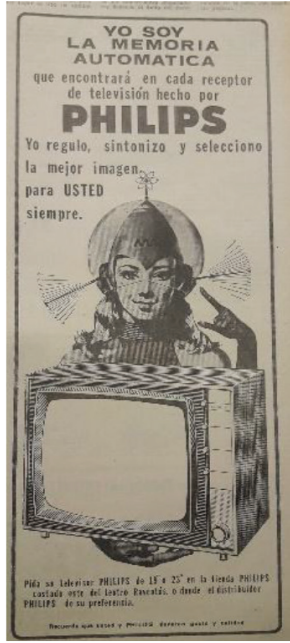

Fuente: La Nación, 12 de marzo de 1968: 21.

Al respecto, es oportuno señalar que la utilización de androides femeninas es un tema que se viene estudiando al menos desde la década de 1980, con trabajos pioneros como los de Haraway, con su «manifiesto para cyborgs» (1995) y, más recientemente, con trabajos como los de Lavigne (2013). En general, como lo plantea Mora-Martínez, hay tres grandes prototipos de «mujeres artificiales»: «... la muñeca-autómata, la malvada androide y la mujer cyborg...» (Mora-Martínez 2011, 334.). En el caso del anuncio citado, la androide que se presenta parece responder al primer tipo, es decir, al de la «muñeca-autómata».

Finalmente, 1969 es el año que presenta el mayor número de anuncios publicitarios de televisores con 26. En este año destacan dos tendencias básicas. La primera de ellas es el anuncio de la televisión a color que la marca Motorola pauta en enero de ese año, señalando que «muy pronto en Costa Rica» va a inaugurar Canal $11^{26}$, mensaje que repite en julio de 1969, al avisar que ya están disponibles sus televisores a color en distintos establecimientos comerciales no solo josefinos, sino de Puntarenas, Alajuela y Grecia ${ }^{27}$.

Al respecto, en este segundo anuncio llama la atención el siguiente texto que se incluye en él: «MUY IMPORTANTE. En su televisor a color Motorola, podrá ver también los programas en blanco y negro» ${ }^{28}$, muestra del desconocimiento que se tenía entonces de la nueva tecnología a color. Adicionalmente, en este anuncio se promociona el televisor a color Motorola como regalo para el Día de la Madre, para «darle vida al regalo de mamá», aspecto sobre el cual se profundizará en el último apartado de este estudio.

Si bien solo se localizan estos dos anuncios referentes a la introducción de la televisión a color, se considera importante consignarlos como evidencia de la llegada incipiente de esa tecnología al país.

La segunda tendencia que se perfila en los anuncios de 1969 es la relación con la era espacial, como sinónimo de actualización tecnológica. En efecto, en este año, en los meses de octubre y

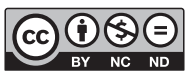


noviembre, se localizan tres anuncios de la marca Admiral, en los cuales la referencia a la era espacial es evidente, los cuales se presentan en las Figuras 7, 8 y 9.

El hecho de que se relacione los televisores con la era espacial no es de extrañar, considerando que unos meses antes se había producido la llegada del ser humano a la Luna, precisamente en julio de 1969. En este caso, la relación se establece a partir de las frases «televisión especial para la era espacial» ${ }^{29}$ e «imagen especial para la era espacial» ${ }^{30}$, en referencia a la calidad de «...la pantalla de 23.000 voltios de potencia...» que hace posible «...que usted sea el protagonista de cada escena...» ${ }^{31}$.

Figura 7

Anuncio de televisores Admiral, 1969

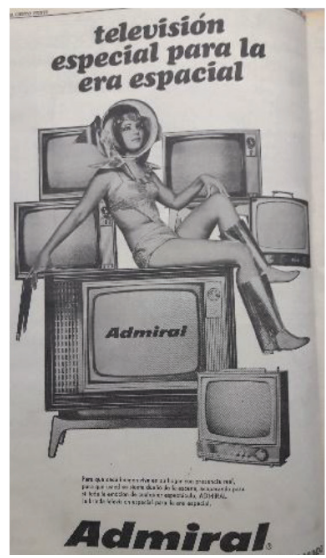

Figura 8

Anuncio de televisores Admiral, 1969

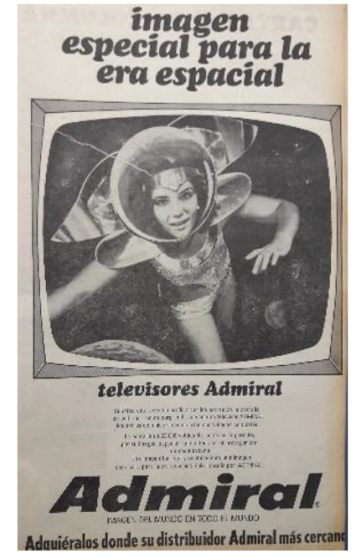

Fuente: La Nación, 12 de octubre de 1969: 120.

Fuente: La Nación, 3 de noviembre de 1969: p. 9.

Figura 9

Anuncio de televisores Admiral, 1969

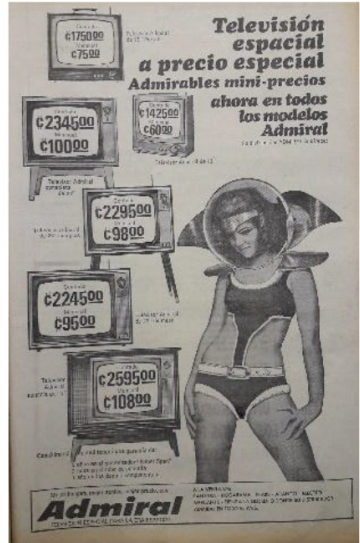

Fuente: La Nación, 3 de diciembre de 1969: 33.

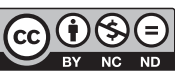


El tercer anuncio de diciembre de 1969 se centra en una oferta de precios bajos o «mini precios» que está ofreciendo en ese mes la marca Admiral, bajo el lema «televisión espacial a precio especial» ${ }^{32}$. No obstante, en los tres casos, la alusión a la era espacial aparece acompañada de una joven figura femenina que tiene un casco en su cabeza y que posee un traje que deja ver gran parte de su cuerpo al descubierto, sin que exista una relación directa entre una cosa y otra, tal y como se explicará en el último apartado de este estudio.

Así, la concentración de anuncios en el último año de la década es explicable en la medida en que ya se conocía más el nuevo medio en el país y, además, ya se contaba con una mayor oferta de canales de televisión, pues a Televisora de Costa Rica se unen en 1965, los canales 6 y 4 (Vega, 1987).

Como puede apreciarse, de alguna forma lo hasta aquí expresado, evidencia el proceso de apropiación de la televisión como un nuevo medio de comunicación y de las mejoras tecnológicas que lo acompañan, al menos desde la perspectiva de la publicidad.

\section{Marcas publicitadas}

Este apartado se centra en las distintas marcas de televisores que se promocionan en la publicidad impresa en la década de 1960. En tal sentido, lo primero que hay que señalar es que en ese período se han localizado 18 marcas de televisores, cuya distribución por cantidad de anuncios se muestra en la Tabla 1. De esas 18 marcas cinco sobrepasan los 10 anuncios, de ahí que este apartado se centrará en el establecimiento de las características de cada una de esas cinco marcas y en los elementos que utilizan para diferenciarse unas de otras.

Tabla 1

Publicidad de televisores por marcas, década de 1960

\begin{tabular}{lcc}
\hline MARCA & $\mathbf{N .}^{\mathbf{0}}$ & \% \\
\hline Admiral & 15 & $11,5 \%$ \\
Dumon & 1 & $1 \%$ \\
General Electric & 1 & $1 \%$ \\
Motorola & 5 & $4 \%$ \\
National & 3 & $2 \%$ \\
Nivico & 2 & $1,5 \%$ \\
Philco & 4 & $3 \%$ \\
Philips & 15 & $11,5 \%$ \\
Sanyo & 19 & $15 \%$ \\
Sharp & 1 & $1 \%$ \\
Siemens & 2 & $1,5 \%$ \\
Singer & 4 & $3 \%$ \\
Sony & 1 & $1 \%$ \\
Sylvania & 14 & $11 \%$ \\
Telefunken & 1 & $1 \%$ \\
Toshiba & 2 & $1,5 \%$ \\
Westinghouse & 3 & $2 \%$ \\
Zenith & 34 & $26 \%$ \\
Sin marca definida & 3 & $2 \%$ \\
\hline TOTAL & $\mathbf{1 3 0}$ & $\mathbf{1 0 0}$ \\
\hline
\end{tabular}

Fuente: Elaboración propia a partir de los anuncios publicitarios recopilados de los periódicos Diario de Costa Rica (1960-1964) y La Nación (1960-1969).

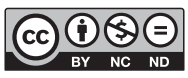


La marca que presenta la mayor cantidad de anuncios publicitarios de televisores es Zenith con 34 anuncios para un $26 \%$ del total. A lo largo de la década, esta marca utiliza un mismo eslogan «lo más fino en televisión», al tiempo que destaca como aspectos básicos de sus televisores, la calidad tanto del aparato de televisión en sí mismo, como del mueble que los acompaña, en este modelo específico. En cuanto al primer aspecto, se destaca el hecho de que los televisores Zenith «...son hechos a mano, cuidadosamente, para garantizar mejor funcionamiento y mayor seguridad ${ }^{33}$. Esta marca también destaca la portabilidad de sus televisores en distintos tamaños y, además, se promocionan como un buen regalo para el Día de la Madre y para Navidad.

La segunda marca en importancia es Sanyo con 19 anuncios $-15 \%$ del total-. Esta marca utiliza como elemento diferenciador frente a la competencia, su experiencia previa en la fabricación de radios, para lo cual utiliza mucho la frase «Sanyo sigue triunfando! No solo en radios a transistores sino que también triunfa en televisores» ${ }^{34}$.

Aparte de esa idea que es central en su publicidad, se apunta que los televisores Sanyo tienen «mejor sonido, mejor claridad de imagen, mejor precio y mejor acabado» ${ }^{35}$. Adicionalmente, esta marca destaca en 1965 y 1966, el uso de un tubo especial llamado «Visualux» que protege la vista ${ }^{36}$.

En el caso de la tercera marca en importancia, hay más bien un empate entre Admiral y Philips, ambas con 15 anuncios -11,5\% del total para cada una-. Admiral utiliza el eslogan «colón por colón Admiral le da más en televisión!» ${ }^{37}$ en repetidas ocasiones a lo largo de la década, aparte de los otros elementos señalados en el apartado anterior, mientras que Philips busca diferenciarse de las otras marcas recurriendo a la experiencia, es decir, a sus 70 años de experiencia en el mercado ${ }^{38}$.

Finalmente, la quinta marca en importancia es Sylvania con 14 anuncios para un 11\% del total. En general esta marca no presenta un eslogan sobre el cual sustentar su publicidad y se basa mucho en las promociones, como, por ejemplo, la reducción de precios en un período determinado, como la que realizó entre febrero y marzo de $1968^{39}$ o el regalar una mesa por la compra de un televisor ${ }^{40}$.

En conclusión, las principales marcas de televisores publicitadas en la década de 1960 buscan diferenciarse de la competencia a partir de elementos como la calidad, la experiencia y las mejoras técnicas de sus componentes.

En ese sentido, es interesante apuntar que, en el caso de los Estados Unidos - país del cual proviene la mayoría de las marcas de televisores publicitadas en Costa Rica- la masificación de la televisión había iniciado con gran fuerza durante la década de 1950. No obstante, a mediados de los años sesenta más del 90\% de los hogares de los Estados Unidos tenían uno o más aparatos de televisión-en comparación con el escaso $10 \%$ de los hogares a inicios de los cincuenta-, aspecto que fue aprovechado por las agencias de publicidad, lo que se traduce en el aumento del gasto publicitario en televisión que pasa de \$1.5 mil millones en 1959 a \$3.5 mil millones en 1969 (Advertising Age 2005), mientras que en el caso de Costa Rica, la televisión estaba comenzando a incursionar apenas en el año 1960.

\section{Publicidad televisiva y mujeres}

En este apartado se buscan establecer los rasgos básicos de la utilización de las imágenes de mujeres en la publicidad impresa de televisores durante la década de 1960, tratando de esbozar algunas posibles explicaciones al respecto.

Una primera tendencia que se puede establecer claramente es el constante recurso al uso de imágenes de mujeres en la publicidad de televisores. Si bien en la década de 1960 los electrodomésticos ligados al entretenimiento familiar toman relevancia -de ahí la presencia de anuncios publicitarios de

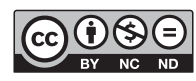

Rev. Reflexiones 98 (2) Julio-Diciembre, 2019: 39-64, E-ISSN: 1659-2859 
productos como radios, consolas, equipos de sonido, tocadiscos y, por supuesto, televisores-, en la publicidad de estos últimos son escasas las referencias al contexto familiar, como una posible explicación de la recurrente utilización de las imágenes de mujeres, partiendo del principio de que su inclusión daría la idea de que el nuevo aparato podría disfrutarse en un ambiente familiar. No obstante, la poca relación que se establece en la publicidad con elementos de la familia no sustenta completamente esa posible explicación, al menos a partir de la muestra utilizada en este estudio.

Por ejemplo, hay cierta alusión al ambiente familiar, en el anuncio del televisor Sony de 5 pulgadas de 1964 que se muestra en la Figura 5, en la que aparecen dos niñas disfrutando de este pequeño aparato. Adicionalmente, en ese mismo anuncio aparece la imagen de una mujer acostada en su cama mirando de lado ese televisor, colocado sobre la mesa de noche ${ }^{41}$. Asimismo, en un anuncio de Motorola de 1968, se muestra una pareja al lado de un televisor, en el cual mientras ella come mirando el televisor, él parece tener en su mano una especie de control remoto de este ${ }^{42}$.

Desde esa perspectiva, Philips es otra marca que hace referencia al disfrute familiar del televisor. Por ejemplo, en dos anuncios, uno de 1961 y otro de 1966, presenta a una familia, compuesta por mamá, papá y una pareja de niños, sentados en un sillón mirando la televisión, al estilo de la publicidad de Estados Unidos que sí recurría mucho a la expectativa del consumo familiar de dicho medio ${ }^{43}$-Figura $10-$.

Figura 10

Anuncio de televisores Philips, 1966

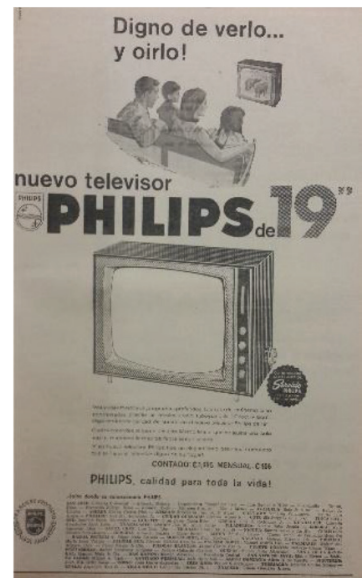

Fuente: La Nación, 11 de mayo de 1966: 17.

En los anuncios de Sanyo, también se localizan dos del año 1962, en los que aparece la imagen de un hombre y una mujer en el centro de las cuales se coloca un televisor, pero sin ninguna alusión directa a un ambiente familiar ${ }^{44}$, mientras que la publicidad de la marca Zenith muestra algunos rasgos novedosos al respecto.

En efecto, en un anuncio de 1968 aparece una familia mirando un televisor, con la misma composición familiar antes descrita ${ }^{45}$. En otro de 1964, se coloca a una pareja de pie mirando un televisor en cuya pantalla aparece un rostro femenino ${ }^{46}$ y, finalmente, en un anuncio de 1969, aparece una pareja sentada en un sillón mirando la televisión, cuya pantalla proyecta también un rostro femenino ${ }^{47}$.

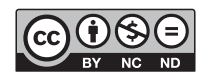


Sin embargo, la marca Zenith exhibe una particularidad importante, como lo es el incluir en su publicidad imágenes de televisores que presentan algo más que un rostro femenino, como sucede en las otras marcas. Esta marca muestra un joven con una bola de baloncesto en sus manos ${ }^{48}$; una pareja ${ }^{49}$; una bailarina de ballet ${ }^{50}$; tres hombres corriendo en lo que parece ser una prueba de atletismo ${ }^{51}$; un hombre tocando una trompeta ${ }^{52}$; una pareja practicando un deporte acuático ${ }^{53}$; un velero surcando el mar ${ }^{54}$; un vaquero montado en un caballo ${ }^{55}$; así como mujeres en situaciones diversas: una cargando un televisor portátil en su casa ${ }^{56}$; otra practicando un deporte no especificado ${ }^{57}$ y una enfermera ${ }^{58}$.

Como se puede apreciar, esta marca diversifica la oferta de imágenes que proyecta en las pantallas de los televisores que coloca en su publicidad, contrariamente al resto de las marcas que más bien insisten en presentar solo rostros de mujeres.

Precisamente esa es una segunda tendencia destacable por predominante: el empleo de rostros femeninos en la publicidad de televisores. Efectivamente, en los anuncios estudiados predomina el empleo de imágenes de mujeres y más específicamente de rostros femeninos en las pantallas de los televisores promocionados, generalmente se trata de mujeres adultas jóvenes -Figura 11- o se presentan solo los ojos de las mujeres -Figura 12-.

Figura 11

Anuncio de televisores Zenith, 1965

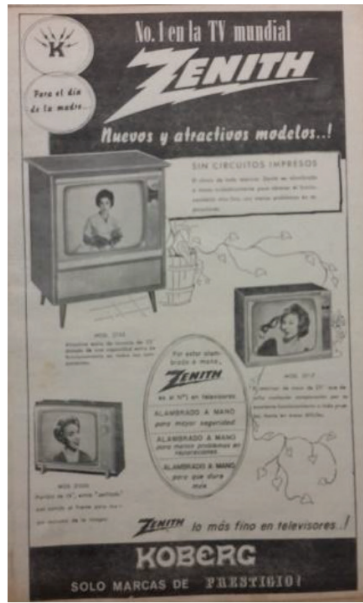

Fuente: La Nación, 1 de agosto de 1965: 9.
Figura 12

Anuncio de televisores Philips, 1960

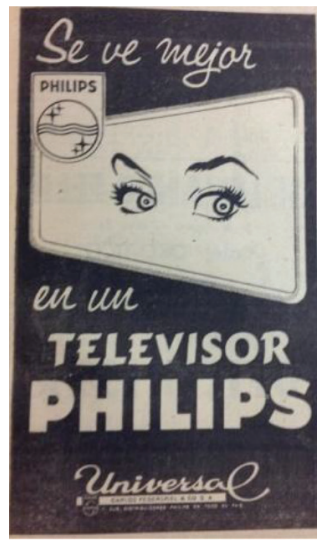

Fuente: La Nación, 19 de febrero de 1960: 11.

Asimismo, en las imágenes de mujeres que aparecen dentro del anuncio, pero fuera de la pantalla, también se utilizan mujeres de ese tipo, aunque conforme transcurre la década y, sobre todo, en sus últimos años, la tendencia es a colocar imágenes de jóvenes, prácticamente adolescentes, en los anuncios, tal y como se ejemplifica en la Figura 13. En este caso, es destacable el uso de una minifalda por parte de la joven del anuncio, una prenda de vestir femenina desarrollada en 1964 por la diseñadora británica Mary Quant (Parga 2015) que se convierte en parte de la «revolución sexual» de las mujeres en ese período.

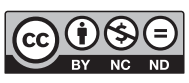

Rev. Reflexiones 98 (2) Julio-Diciembre, 2019: 39-64, E-ISSN: 1659-2859 


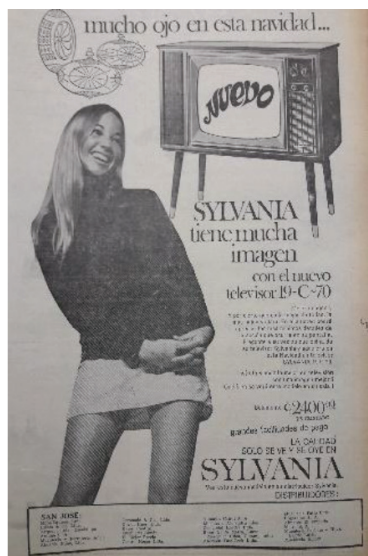

Fuente: La Nación, 2 de diciembre de 1969: 33.

Dentro de esta perspectiva, ¿en qué tipo de situaciones son presentadas las mujeres en la publicidad de televisores? En general, ellas se muestran usando desde trajes espaciales y poca ropa (Figuras 7, 8 y 9) hasta como presentadoras para mostrar un determinado modelo de televisión, caso en el que aparecen junto al producto -Figura 14-, ya sea presentándolo con su mano o simplemente ubicándose al lado de este e incluso sentándose sobre él -Figura 15-. Generalmente, su postura es llamativa, utilizan sobre todo vestidos y tacones altos y se presentan bien arregladas, aunque ya en un caso una modelo utiliza pantalones -Figura 16-.

Figura 14

Anuncio de televisores Siemens, 1962

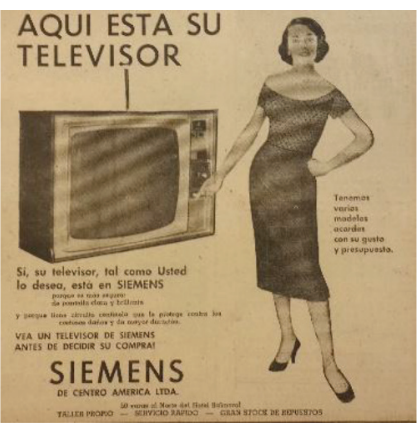

Fuente: La Nación, 12 de noviembre de 1962: 13
Figura 15

Anuncio de televisores Sylvania, 1966

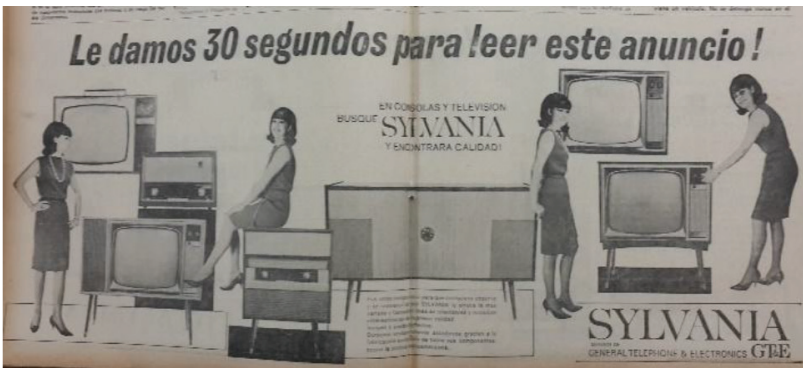

Fuente: La Nación, 17 de mayo de 1966: 33. 


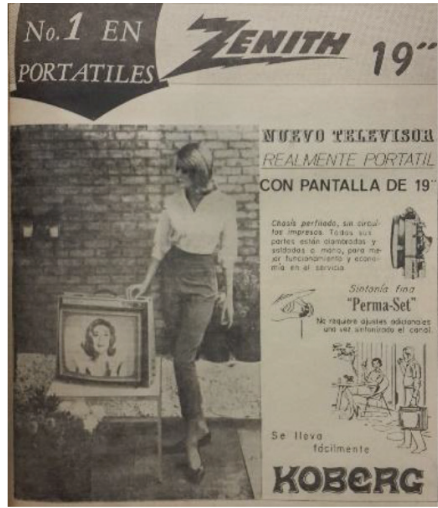

Fuente: La Nación, 21 de octubre de 1963: 25

Este hecho merece destacarse debido a que es en la década de 1960 cuando comienza a popularizarse con mayor fuerza el uso de esta prenda por parte de las mujeres, la cual, pese a que se vincula con la pérdida de su feminidad, llegará a convertirse en parte de su cotidianidad, situación que, como se aprecia en el anuncio citado, se verá estimulada por la publicidad.

Adicionalmente, ¿qué mujeres son las que aparecen en los anuncios de televisores? Básicamente se trata de mujeres que, por el aspecto antes descrito, parecen ser de clase media e incluso jóvenes, un público que adquiere relevancia en el contexto de los movimientos sociales de la década de 1960 (Gourley 2008.). En ambos casos, muy posiblemente se utilizan las imágenes de estas mujeres, por su incorporación creciente a la educación incluso superior, al mercado laboral y por estar más dispuestas al cambio, es decir, son mujeres que van a la vanguardia dada su misma condición social que en alguna medida desafía el lugar tradicionalmente asignado a las mujeres, es decir, en el caso de las de clase media, se trata de mujeres con cierta capacidad de compra y con educación, algunas incluso universitaria, lo cual sin duda era un aspecto fundamental en el proceso de introducción del nuevo medio de comunicación al país.

Por ejemplo, es importante recordar que, de acuerdo con los datos del Censo de Población de 1963, las mujeres representaban el 50,1\% de la población alfabeta del país (Dirección General de Estadística y Censos, 1966c, 474), el 55\% de las 12.195 personas graduadas universitarias (Dirección General de Estadística y Censos, 1966d, 530) y el 16,2\% de la población económicamente activa (Dirección General de Estadística y Censos, 1966b, 26).

Por otra parte, se debe tener presente que la utilización de la imagen de las mujeres para promocionar distintos tipos de productos es una tendencia internacional de la publicidad que ha estado presente desde las primeras décadas del siglo XX, pero que se acentúa sobre todo a partir de la década de 1920, cuando las mujeres son reconocidas por la publicidad como consumidoras. En este sentido, tal y como lo muestran diversas investigaciones, ya en la primera década del siglo XX la principal agencia de publicidad de los Estados Unidos, la J. Walter Thompson, reconocía que el 85\% de las compras -especialmente del hogar- eran realizadas por mujeres (Hill 2002; Marchand 1986; Sivulka 1998).

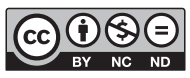


El reconocimiento de las mujeres como consumidoras, va unido a los logros económicos y sociales que ellas van alcanzando en distintos contextos sociales -como el derecho al sufragio femenino en 1920 en los Estados Unidos (Hill 2002) -, país del que llegan muchos de los anuncios publicitarios que se difunden en los periódicos costarricenses.

Aunado a lo anterior, es interesante apuntar que, en los Estados Unidos en la década de 1930, en el contexto de la depresión económica, las mujeres básicamente de clase media se agrupan en una serie de organizaciones para luchar por temas como los precios justos de los productos, situación en la cual ya actúan como ciudadanas y como consumidoras, es decir en su calidad de esposas y de madres actuaban en defensa de los intereses de sus familias y como ciudadanas se movilizaban en el espacio público para exigir políticas públicas sobre consumo que protegieran a la ciudadanía de ese país en general (Cohen 2004, 31-41).

En tal sentido, más allá de una figura «decorativa», las mujeres se utilizan en la publicidad de televisores en su condición de posibles consumidoras de este nuevo producto, tanto por su capacidad para comprarlo o para influir en la decisión de compra de este en el hogar, pero, sobre todo, como consumidoras en potencia de la nueva propuesta de entretenimiento que representaba la televisión. Recuérdese que la televisión -al igual que la radio- es un medio de comunicación que llega directamente al hogar, el lugar por excelencia de las mujeres dedicadas al hogar, tradicionalmente llamadas amas de casa, las cuales podrían convertirse en su principal consumidora en él, bajo la perspectiva de la felicidad que conlleva el consumo mediático, en este caso de la televisión.

Además, habría que considerar también el proceso de tecnificación del hogar que se produce desde la década de 1950, con la introducción de los electrodomésticos, con el objetivo de «facilitarle» a las mujeres las labores del hogar y, dentro de esa visión, tener más tiempo libre para su familia (Pelta 2012). Precisamente es en este contexto en el cual se inscribe la televisión, un medio que abre la posibilidad de que las mujeres puedan disfrutar de entretenimiento o de tiempo de ocio en el mismo hogar, es decir, en el mismo espacio privado en que realizan el trabajo doméstico, sin necesidad de desplazarse al espacio público.

De acuerdo con Spigel (1992) -que estudia el caso de los Estados Unidos-, la televisión vino a redefinir la división que predominaba desde el siglo XIX entre tiempo de trabajo y tiempo de ocio, dentro de la cual, el espacio privado del hogar era un lugar de consumo y el espacio público lo era del trabajo productivo. No obstante, en el caso de las mujeres, el hogar ha sido tradicionalmente el espacio para el trabajo doméstico, de ahí que, con la introducción de la televisión, este se convierte también en un lugar de esparcimiento para las mujeres, idea que tomaron en cuenta las grandes cadenas estadounidenses productoras de contenido televisivo como NBC, CBS y ABC, no sin antes pasar por un período de incertidumbre en el sentido de que dada la atención que requería la televisión, era posible que las amas de casa no pudieran verla por cumplir con sus obligaciones en el hogar.

No obstante, esta situación se fue resolviendo mediante el manejo de la producción diaria y su adaptación a los distintos horarios de las labores hogareñas llevadas a cabo por las amas de casa, e incluso utilizando en un principio un formato de programas parecido al de la radio, elementos a los que se une la introducción de la publicidad televisiva, es decir, de los programas patrocinados por marcas o productos específicos a lo largo de las décadas de 1950 y 1960, muchos de los cuales eran utilizados directamente en las tareas del hogar con el fin de llamar la atención de las amas de casa (Spigel 1992, 73-98).

En concordancia con lo anterior, un caso que destaca por su singularidad dentro de la muestra de anuncios estudiados, es uno en el que aparece una ama de casa, incluso con su delantal -una de las

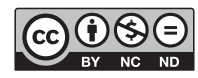

Rev. Reflexiones 98 (2) Julio-Diciembre, 2019: 39-64, E-ISSN: 1659-2859 
formas tradicionales de representación de las mujeres dedicadas a las labores del hogar en la publicidad-, al lado de un televisor y con una postura de felicidad frente a él, imagen que se acompaña del texto «por fin llegó» ${ }^{59}$-Figura 17-, haciendo referencia a la llegada del televisor National «la respuesta perfecta a las necesidades de todos los hogares costarricenses» ${ }^{60}$, uno de los pocos anuncios que menciona la palabra «hogar»y que hace referencia directa al contexto costarricense.

Figura 17

Anuncio de televisores National, 1960

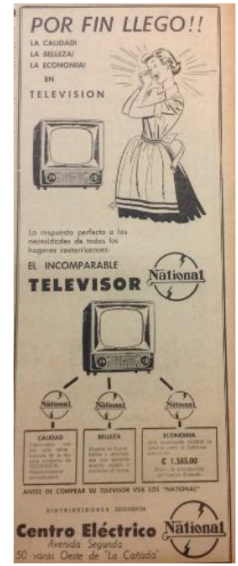

Fuente: La Nación, 17 de mayo de 1960: 3.

Si bien la referencia al ama de casa es propia de este anuncio, es importante mencionarla, pues puede ser un indicio del tipo de publicidad que se presente en décadas posteriores, en cuanto al entretenimiento que un televisor podría implicar para ella, dada su permanencia casi constante en el hogar, idea que concuerda con los planteamientos antes propuestos.

Otra dimensión importante de considerar en ese mismo sentido es la de regalar televisores para el Día de la Madre, a pesar de que todavía en la década de 1960 era muy incipiente la expansión de la televisión en el país. De este tipo se localizaron 19 anuncios. En ellos se promocionan los televisores como un regalo para mamá, pero sin ahondar en las razones por las cuales ella se sentirá «feliz y sorprendida» con un obsequio de este tipo. Más bien lo que se hace en estos anuncios es destacar las cualidades técnicas del modelo que se promueve como regalo para ella. Solo en uno de esos 19 anuncios, se hace una referencia directa a los beneficios que mamá obtendrá con el obsequio de un televisor. Se trata de un anuncio de la marca Philips del año 1960, en el cual se apunta lo siguiente: «regálele en su día, días de alegría, días de entretenimiento con un Televisor PHILIPS 1960 y Ud. también se sentirá dichoso y feliz al verla disfrutando de esos momentos agradables» ${ }^{61}$.

El texto anterior es relevante pues es el único de los anuncios utilizados en esta investigación, en el cual se hace referencia a la posibilidad de entretenimiento que le brinda el televisor a las mujeres en su condición de amas de casa y madres, texto que se acompaña de la tradicional imagen maternal de una mujer abrazando un niño en sus brazos, la que se muestra en la pantalla del televisor publicitado -Figura 18-. Incluso esa imagen tan tradicional solo está presente en ese anuncio directamente en la

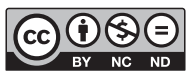


pantalla del televisor, mientras que en otros dos aparece una madre abrazando a su hijo, pero fuera de la pantalla ${ }^{62}$.

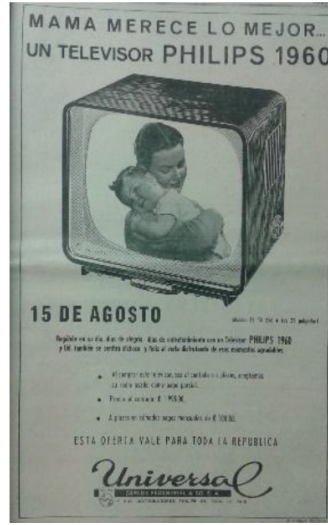

Fuente: La Nación, 26 de julio de 1960: 3.

En síntesis, cabe destacar la asociación que hace la publicidad entre la felicidad y el consumo mediático, en este caso concreto entre la televisión y el entretenimiento de las mujeres, en especial de las amas de casa, quienes, como madres sacrificadas y esposas abnegadas, sin dejar de lado sus tareas hogareñas, podrían disfrutar ahora de los momentos de ocio y felicidad que brinda la televisión, estrategia publicitaria que seguía limitando el papel de las mujeres al espacio privado del hogar.

\section{Reflexiones finales}

Para concluir esta investigación interesa resaltar dos elementos básicos. En primer lugar, dado que la televisión como nuevo medio de comunicación ingresa al país en 1960, su apropiación es todavía incipiente a lo largo de la década, por lo que este trabajo es apenas un esbozo general de cómo desde la publicidad se inducía a consumir el nuevo medio, así como las estrategias empleadas por esta para promocionar un producto que era desconocido aún para la gran mayoría de la población costarricense de entonces.

En tal sentido, interesa mostrar la relevancia que pueden tener este tipo de estudios para comprender mejor el papel de los medios de comunicación en el país y su relación con aspectos fundamentales como la apropiación de estos en los hogares costarricenses y el lugar de las mujeres en esos procesos, sobre todo considerando la influencia que aún posee la televisión en la actualidad.

Lo anterior se relaciona con el énfasis puesto en los aspectos tecnológicos del nuevo medio y en las mejoras que las distintas marcas fueron implementando en sus aparatos a lo largo de la década, es decir, se aprecia un proceso de diferenciación de marcas basado en los aspectos tecnológicos más que en la experiencia que podía representar el uso del nuevo medio de comunicación para la población consumidora, de ahí que aspectos como la novedad, el tamaño de la pantalla -cada vez más grande-,

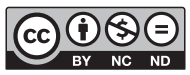


pero también la portabilidad, es decir, la posibilidad de tener televisores pequeños que facilitaran su uso en diferentes espacios y contextos, representan la apuesta de la publicidad para introducir la televisión en el país.

Así, los distintos modelos de televisores, ya fuera de tipo consola o mueble, de mesa o portátiles, implicaban ya de por sí diferentes formas de consumo, tanto dentro del hogar o incluso fuera de él, sobre todo en el caso de los televisores más pequeños.

En segundo lugar, en relación con la utilización constante de imágenes de mujeres en los anuncios publicitarios de los televisores y su relación con la introducción y el consumo hogareño del nuevo medio de comunicación, se ha tratado de superar la mera explicación de su presencia en función de un uso de dichas imágenes para llamar la atención sobre todo del público masculino, en favor de una explicación que relacione este hecho con las tendencias publicitarias internacionales presentes desde inicios del siglo XX y con el reconocimiento de las mujeres como un público meta fundamental para la publicidad en función de su papel como consumidoras y encargadas mayormente del consumo de sus hogares, situación que no representa necesariamente una mejora de las mujeres en cuanto a una mayor visibilización de estas en los espacios públicos, sino que seguía limitando su accionar al entorno hogareño y, sobre todo, a su papel de esposas y madres.

Sin embargo, más allá de eso, el hecho de que la televisión irrumpa directamente en los hogares y que las que permanecen más tiempo en ellos sean tradicionalmente las amas de casa, convierte a las mujeres en un público potencialmente relevante para consumir los contenidos que la televisión ofrece, es decir, se logra unir en el espacio privado del hogar, el trabajo doméstico con el entretenimiento, abriendo la posibilidad de que las mujeres puedan disfrutar de tiempo de entretenimiento y de ocio sin salir de él, con las implicaciones que esto representa para ellas en términos de una mayor incursión en el espacio público, tema sin duda de futuras investigaciones para el caso costarricense.

En síntesis, la televisión que ingresa al país en 1960 llegó para quedarse y para jugar un papel cada vez más significativo en la Costa Rica de las décadas siguientes, contribuyendo a destacar el papel de las mujeres como consumidoras de la pantalla chica, hasta convertirse en un poderoso medio de comunicación cuya influencia en las percepciones de la población costarricense es todavía preponderante.

\section{Agradecimientos}

La autora agradece a la Dra. Vanessa Fonseca sus comentarios y observaciones a una primera versión de esta investigación. Asimismo, agradece la asistencia de Eddson Gómez, Erick Gómez, Andrey Barrantes, estudiantes de la Escuela de Ciencias de la Comunicación Colectiva y de Verónica Pérez, estudiante de Educación Primaria, ambas escuelas de la Universidad de Costa Rica, en la recopilación de la información para este estudio.

\section{Notas}

1. La Nación, 16 de mayo de 1960: 11.

2. La Nación, 16 de mayo de 1960: 11.

3. La Nación, 7 de enero de 1960: 2.

4. La Nación, 27 de noviembre de 1960: 9.

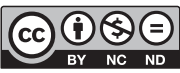

Rev. Reflexiones 98 (2) Julio-Diciembre, 2019: 39-64, E-ISSN: 1659-2859 
5. Diario de Costa Rica, 11 de noviembre de 1960: 3.

6. La Nación, 17 de mayo de 1960: 3.

7. La Nación, 28 de abril de 1960: 7.

8. La Nación, 21 de julio de 1961: 9.

9. La Nación, 28 de noviembre de 1961: 29; La Nación, 21 de julio de 1961: 9.

10. La Nación, 27 de febrero de 1962: 9; La Nación, 9 de marzo de 1962: 9. En cuanto al Canal 9 es necesario aclarar que fue la frecuencia televisiva que originalmente le fue otorgada a Arnoldo Vargas, quien la utilizó bajo el nombre de Radio Televisión Tic-Tac Limitada hasta 1978, cuando cambia a Multivisión de Costa Rica. No obstante, dado que Canal 9 tenía poca cobertura geográfica, Vargas compra la frecuencia de Canal 4, la cual le permitía cubrir una mayor parte del territorio nacional (Vega 1987, 83-84).

11. La Nación, 27 de febrero de 1962: 9.

12. La Nación, 16 de setiembre de 1962: 17.

13. La Nación, 18 de enero de 1962: 3.

14. Diario de Costa Rica, 6 de enero de 1963: 5.

15. Diario de Costa Rica, 1 de diciembre de 1963: 5; La Nación, 21 de octubre de 1963: 25.

16. La Nación, 26 de setiembre de 1963: 41.

17. La Nación, 22 de diciembre de 1963: 14.

18. La Nación, 13 de abril de 1964: 56.

19. La Nación, 5 de enero de 1964: 17.

20. La Nación, 5 de enero de 1964: 17.

21. La Nación, 26 de abril de 1965: 23.

22. La Nación, 26 de abril de 1966: 7.

23. La Nación, 11 de mayo de 1966: 17.

24. La Nación, 12 de marzo de 1968: 21.

25. La Nación, 12 de marzo de 1968: 21.

26. La Nación, 22 de enero de 1969: 31.

27. La Nación, 17 de julio de 1969: 31.

28. La Nación, 17 de julio de 1969: 31. 
29. La Nación, 12 de octubre de 1969: 120.

30. La Nación, 3 de noviembre de 1969: 9.

31. La Nación, 3 de noviembre de 1969: 9.

32. La Nación, 3 de diciembre de 1969: 33.

33. La Nación, 15 de febrero de 1960: 5.

34. La Nación, 21 de octubre de 1962: 27.

35. Diario de Costa Rica, 6 de enero de 1963: 5

36. La Nación, 28 de mayo de 1965: 3; La Nación, 3 de agosto de 1966: 3.

37. La Nación, 13 de marzo de 1960: 57.

38. Diario de Costa Rica, 30 de mayo de 1963: 3.

39. La Nación, 17 de febrero de 1968: 9.

40. La Nación, 20 de noviembre de 1969: 13.

41. La Nación, 5 de enero de 1964: 17.

42. La Nación, 9 de diciembre de 1968: 39.

43. Diario de Costa Rica, 14 de febrero de 1961: 7 y La Nación, 11 de mayo de 1966: 17.

44. La Nación, 17 de octubre de 1962: 40 y Diario de Costa Rica, 14 de noviembre de 1962: 19.

45. La Nación, 10 de diciembre de 1968: 3.

46. La Nación, 6 de diciembre de 1964: 17.

47. La Nación, 5 de diciembre de 1969: 55.

48. Diario de Costa Rica, 12 de agosto de 1960: 3.

49. Diario de Costa Rica, 30 de octubre de 1960: 11 y Diario de Costa Rica, 9 de diciembre de 1963: 3 .

50. $\quad$ Diario de Costa Rica, 4 de agosto de 1961: 5.

51. Diario de Costa Rica, 5 de agosto de 1962: 5.

52. $\quad$ Diario de Costa Rica, 4 de agosto de 1963: 11.

53. Diario de Costa Rica, 1 de diciembre de 1963: 5.

54. Diario de Costa Rica, 9 de diciembre de 1963: 3 .

55. La Nación, 16 de julio de 1963: 21.

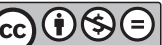


56. La Nación, 17 de mayo de 1964: 29.

57. La Nación, 22 de noviembre de 1964: 25.

58. La Nación, 29 de noviembre de 1964: 19.

59. La Nación, 17 de mayo de 1960: 3.

60. La Nación, 17 de mayo de 1960: 3.

61. La Nación, 26 de julio de 1960: 3 .

62. Diario de Costa Rica, 12 de agosto de 1960: 3; La Nación, 10 de agosto de 1966: 15.

\section{Referencias}

Advertising Age. 2005, March 28. 1960s Creativity and breaking the rules. http://adage.com/ article/75-years-of-ideas/1960s-creativity-breaking-rules/102704/

Cohen, Lizabeth. 2004. A Consumers' Republic. The Politics of Mass Consumption in Postwar America. New York, United States: Vintage Books.

Corrales, Gloriana. 2017. «Especial 70 aniversario: La llegada de la televisión: El día en que Costa Rica despertóaunanuevaera».LaNación,26deagosto.https://www.nacion.com/revista-dominical/especial70-aniversario-la-llegada-de-la-television-el-dia-en-que-costa-rica-desperto-a-una-nueva-era/ TAQUV7NPCRBYTI4AEER4RD666U/story/

Dirección General de Estadística y Censos. 1966a. Censo de población de 1963. Cuadro 1. Población total, urbana y rural de Costa Rica, según sexo, por provincias, cantones y distritos. San José, Costa Rica: Dirección General de Estadística y Censos. http://ccp.ucr.ac.cr/bvp/censos//1963/pdf/ cuadro01-63.pdf

Dirección General de Estadística y Censos. 1966b. Censo de población de 1963. Cuadro 7. Población activa (12 años y más) urbana y rural de Costa Rica, según: ocupación, rama de actividad y sexo. San José, Costa Rica: Dirección General de Estadística y Censos. http://ccp.ucr.ac.cr/bvp/ censos//1963/pdf/cuadro07_01-63.pdf

Dirección General de Estadística y Censos. 1966c. Censo de población de 1963. Cuadro 65. Alfabetismo y analfabetismo de la población de 10 años y más, urbana y rural, según sexo y grupos de edad, por provincias. San José, Costa Rica: Dirección General de Estadística y Censos. http:// ccp.ucr.ac.cr/bvp/censos//1963/pdf/cuadro65-63.pdf

Dirección General de Estadística y Censos. 1966d. Censo de población de 1963. Cuadro 74. Graduados universitarios en la población total, urbana y rural de Costa Rica, según sexo y número de años aprobados. San José, Costa Rica: Dirección General de Estadística y Censos. http://ccp.ucr.ac.cr/ bvp/censos//1963/pdf/cuadro73-74-63.pdf

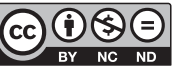


Duke University. Digital Repository. Ad*Access. John W. Hartman Center for Sales, Advertising \& Marketing History. https://repository.duke.edu/dc/adaccess?f\%5Bproduct_facet _sim\%5D\%5B\%5D=Television

Gourley, Catherine. 2008. Gidgets and Women Warriors. Perceptions of Women in the 1950s and 1960s. Minneapolis, United States: Twenty-First Century Books.

Haraway, Donna. 1995. Ciencia, cyborgs y mujeres: la reinvención de la naturaleza. Madrid: Ediciones Cátedra. http://kolectivoporoto.cl/wp-content/uploads/2015/11/Haraway-Donna-ciencia-cyborgsy-mujeres.pdf. Edición en PDF.

Heimann, Jim, ed. 2005. The Golden Age of Advertising - the 60s. Madrid, España: Taschen.

Hill, Daniel. 2002. Advertising to the American Woman 1900-1999. Columbus, United States: Ohio State University Press.

Lavigne, Carlen. 2013. Cyberpunk Women, Feminism and Science Fiction. A Critical Study. Jefferson, North Carolina, United States: McFarland \& Company, Inc., Publishers. Edición en PDF.

Marchand, Roland. 1986. Advertising the American Dream. Making Way for Modernity, 1920-1940. California, United States: University of California Press.

Mora-Martínez, Martín. 2011. «Cyborgs y mujeres artificiales: apuntes sobre género y cultura». $L a$ ventana. Revista de estudios de género, 33: 334-344. http://revistalaventana.cucsh.udg.mx/index. php/LV/article/viewFile/850/804

Parga, Mónica. 2015. «Honores para la minifalda de Mary Quant». El País, 19 de enero. https://elpais. com/elpais/2015/01/15/estilo/1421324931_466725.html

Pelta, Raquel. 2012. «El nuevo ángel del hogar. Electrodomésticos y publicidad (1880-1960)». Pensar la Publicidad, 6: 117-146. Doi: http://dx.doi.org/10.5209/rev_PEPU.2012.v6.40640

Sivulka, Juliann. 1998. Soap, Sex, and Cigarettes. A Cultural History of American Advertising. Belmont, United States: Wadsworth Publishing Company.

Spigel, Lynn. 1992. Make Room For TV. Television and the Family Ideal in Postwar America. Chicago, United States: The University of Chicago press.

The Advertising Archives. http://www.advertisingarchives.co.uk/en/page/show_home_page.html Vega, Patricia. 1987. Historia de la televisión en Costa Rica. San José, Costa Rica: inédito.

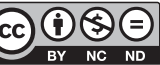




\section{Fuentes primarias}

«15 de agosto», La Nación, 21 de julio de 1961: 9.

«Abra usted las ventanas para ver un mundo nuevo y encantador con televisión Philips», La Nación, 16 de mayo de 1960: 11.

«Admiral», La Nación, 13 de marzo de 1960: 57.

«Ahora dos canales de televisión... y esta maravillosa oferta de Philco», La Nación, 9 de marzo de 1962: 9.

«Ahora GRATIS para su mamá», Diario de Costa Rica, 5 de agosto de 1962: 5.

«AHORA, LO MEJOR A SU ALCANDE...POR QUÉ CONFORMARSE CON MENOS?, » La Nación, 10 de diciembre de 1968: 3.

«ALMACEN KOBERG y sus Distribuidores Sylvania le ofrecen el televisor que más le conviene...!», La Nación, 10 de agosto de 1966: 15.

«AQUI ESTA SU TELEVISOR», La Nación, 12 de noviembre de 1962: 13.

«ATENCION», La Nación, 15 de febrero de 1960: 5.

«Calidad es la razón por la cual ZENITH ES EL NO. 1 EN LA TV MUNDIAL», Diario de Costa Rica, 9 de diciembre de 1963: 3.

«DELE VIDA AL REGALO DE MAMA CON UN TELEVISOR A COLOR MOTOROLA», La Nación, 17 de julio de 1969: 31.

«Dése el lujo de comprar Motorola», La Nación, 9 de diciembre de 1968: 39.

«Digno de verlo... y oírlo! », La Nación, 11 de mayo de 1966: 17.

«iEL REGALO QUE MAMÁ ESPERA!», La Nación, 3 de agosto de 1966: 3.

«Es la calidad lo que hace a Zenith el No.1 a nivel mundial», La Nación, 22 de diciembre de 1963: 14.

«Este televisor Zenith sigue funcionando aun sacándolo 38 partes! », La Nación, 22 de noviembre de 1964: 25.

«Facilísimo! Comodísimo! Novísimo», La Nación, 18 de enero de 1962: 3.

«GRAN TELEPROMOCIÓN DE SYLVANIA», La Nación, 17 de febrero de 1968: 9.

«Hágala feliz con el mejor televisor Zenith», Diario de Costa Rica, 12 de agosto de 1960: 3.

«Imagen especial para la era espacial», La Nación, 3 de noviembre de 1969: 9.

«Koberg», Diario de Costa Rica, 4 de agosto de 1961: 5.

«KOBERG», La Nación, 27 de febrero de 1962: 9.

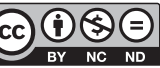

Rev. Reflexiones 98 (2) Julio-Diciembre, 2019: 39-64, E-ISSN: 1659-2859 
«KOBERG. Feliz Navidad con un televisor Zenith», La Nación, 28 de noviembre de 1961: 29.

«KOBERG. ¡La novedad en televisión...», La Nación, 5 de enero de 1964: 17.

«Le damos 30 segundos para leer este anuncio! », La Nación, 17 de mayo de 1966: 33.

«Le regalamos esta mesa... qué mesa», La Nación, 20 de noviembre de 1969: 13.

«LO MEJOR PARA OBSEQUIAR... LO MEJOR PARA RECIBIR», La Nación, 29 de noviembre de 1964: 19.

«Lo nuevo en este televisor tiene 70 años!», Diario de Costa Rica, 30 de mayo de 1963: 3.

«MAMA MERECE LO MEJOR... UN TELEVISOR PHILIPS 1960», La Nación, 26 de julio de 1960: 3.

«Mucho ojo en esta navidad...», La Nación, 2 de diciembre de 1969: 33.

«No.1 en la TV mundial Zenith», La Nación, 1 de agosto de 1965: 9.

«No. 1 en portátiles Zenith 19», La Nación, 21 de octubre de 1963: 25.

«Nosotros nunca olvidamos lo mucho que usted confía en Westinghouse», La Nación, 26 de setiembre de 1963: 41

«NUEVO CONCEPTO EN ESTILO PERFILADOS...», La Nación, 17 de mayo de 1964: 29.

«Nuevo modelo Zenith», La Nación, 6 de diciembre de 1964: 17.

«Obtenga ahora el "Acompañante" Zenith 12» PORTATIL», La Nación, 26 de abril de 1965: 23.

«Otra gran oportunidad Sanyo», La Nación, 26 de abril de 1966: 7.

«Para esta Navidad ponga su ojo en Zenith», La Nación, 5 de diciembre de 1969: 55.

«Ponga su ojo en Zenith», Diario de Costa Rica, 30 de octubre de 1960: 11.

«POR FIN LLEGÓ!!», La Nación, 17 de mayo de 1960: 3.

«Pruebe Philips», Diario de Costa Rica, 14 de febrero de 1961: 7.

«Qué feliz sorpresa...», La Nación, 16 de julio de 1963: 21.

«Realismo en imagen y sonido», Diario de Costa Rica, 11 de noviembre de 1960, 3 .

«Realismo en imagen y sonido», La Nación, 27 de noviembre de 1960: 9.

«Regale lo más fino en televisión! », Diario de Costa Rica, 4 de agosto de 1963: 11.

«SANYO EL PRIMERO...», Diario de Costa Rica, 14 de noviembre de 1962: 19.

«SANYO SIGUE DE PRIMERO...», La Nación, 17 de octubre de 1962: 40.

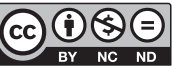


«SANYO SIGUE TRIUNFANDO! NO SOLO EN RADIOS A TRANSISTORES SINO QUE TAM-

BIÉN TRIUNFA EN TELEVISORES», La Nación, 21 de octubre de 1962: 27.

«SANYO VIGILA SUS OJOS...», La Nación, 28 de mayo de 1965: 3.

«Se ve mejor en un TELEVISOR PHILIPS», La Nación, 19 de febrero de 1960: 11.

«Se ve y se escucha mejor... si es Philips su televisor», La Nación, 7 de enero de 1960: 2.

«Si desea “CALIDAD”, compre un Zenith», La Nación, 28 de abril de 1960: 7.

«Sí tiene... Mejor sonido. Mejor claridad de imagen. Mejor precio y Mejor acabado...», Diario de Costa Rica, 6 de enero de 1963: 5.

«Solo Philips pudo lograrlo», La Nación, 16 de setiembre de 1962: 17.

«TELEVISION A COLOR», La Nación, 22 de enero de 1969: 31.

«Televisión espacial a precio especial», La Nación, 3 de diciembre de 1969: 33.

«Televisión especial para la era espacial», La Nación, 12 de octubre de 1969: 120.

«Una exclusividad Sanyo. Garantía total», La Nación, 13 de abril de 1964: 56.

«YO SOY LA MEMORIA AUTOMÁTICA que encontrará en cada receptor de televisión hecho por PHILIPS». La Nación, 12 de marzo de 1968: 21.

«Zenith Jetstar», Diario de Costa Rica, 1 de diciembre de 1963: 5. 